\title{
Impact of intrinsic motivation in professional success: an empirical approach
}

\author{
Patricia Ruiz-Martin
}

\begin{abstract}
This study is an attempt to define the key internal factors that have any impact into building the intrinsic motivation and external agents that can be shaped in order to enhance the individual's efficiency within an organization.

Although, there may be thousands of different definitions for motivation, there are three main aspects to highlight and that are common to every theory. Motivation is understood as some sort of energy associated to behaviour, it is also what drives people to act in a particular way and last but not least, it is something relative to the individual in itself.

There are two differentiated components within the concept of motivation: extrinsic motivation, which is mainly the external means that encourage the individual based upon on performance. These factors will also make the individual adopt a specific position towards some situations and repeat the behaviour if a positive feedback or a reward is provided; and intrinsic motivation, the factors related to this motivation, are associated mainly to the activity/ project in itself, for its own value and impact on others (clients, suppliers, organizations).

Employees may opt for shaping their jobs to an extent that they can actually enjoy and challenge themselves, helped by those internal motivators that can make the individual be really motivated and willing to do its best at work. Redesigning jobs it is widely called "job crafting" and it relates to the way individual copes with both tasks and other employees of the organization.
\end{abstract}

Keywords-motivation, strength, individual, extrinsic, intrinsic, factors, job crafting.

\section{Evolution of the approach to motivation}

What is motivation? This is a word that comes from Latin "motivus" or "motus" which can be translated as movement, according to its etymological meaning, motivation will be considered as the force or impulse that drives and inspires individuals to act accordingly.

Authors have referred to motivation in many different ways and it has incredibly evolved as time has gone on. It is considered that the first speculations about motivation were made back on year $30 \mathrm{BC}$. This was the peak time of the classic philosophy but, due to the lack of systematic experimental research tools at this time, it was not until the beginning of the nineteenth century that the research about brain's structure and its functionality was initiated enhancing the development of stronger theories about motivation and its diverse associated statuses. It was finally in 1920 when the concept of motivation was firstly used as it is known today.

\section{Patricia Ruiz-Martin}

Program Support Coordinator

Kelly OCG - Kelly Services

Telford - Birmingham, United Kingdom
According to Bartol and Martin (1998), motivation is "the force that stimulates behaviour, provides direction to behaviour and underlies the tendency to prevail". In other words, these authors state that individuals should find the strength to pursue and achieve their goals in themselves, in order to be able to keep up the energy levels required to achieve long term goals.

On the other hand, there are researchers such as Victor H. Vroom (1964) that define motivation as "a process governing choices among alternative forms of voluntary activities, a process controlled by the individual. The individual makes choices based on estimates of how well the expected results of a given behaviour are going to match up with or eventually lead to the desired results. Motivation is a product of the individual's expectancy that a certain effort will lead to the intended performance, the instrumentality of this performance to achieving a certain result, and the desirability of this result for the individual, known as valence."

One of the most well-known theories regarding motivation is Maslow's hierarchy of needs (1943). The hierarchy remains a very popular framework in sociology research, management training and secondary and higher psychology instruction.

This theory is mostly represented by a pyramid stating 5 different levels: Physiological needs, Safety needs, Love and Belonging needs, Esteem needs and Self-actualization needs. The first 4 levels can be grouped as "deficiency needs" or "d-needs" and the next and last level will be "being needs" or "b-needs".

Maslow states that the most basic level of needs, "Physiological needs", that covers breathing, food, water and sleep amongst others, must be met before the individual demands safety needs such as security of body, of employment, of health, of family etc. These two first levels' needs will need to be met before aspiring to meet love and belonging needs. The next level of individual needs includes self-esteem, confidence, respect by and of others and achievement. Once these four levels of "deficiency needs" are met, the individual will be on the top of the pyramid aspiring to increase his/her spontaneity, morality and creativity, ability to solve problems or lack of any kind of prejudices.

Although, there may be thousands of different definitions for motivation, there are three main aspects to highlight and that are common to every theory. Motivation is understood as some sort of energy associated to behaviour, it is also what drives people to act in a particular way and last but not least, it is something relative to the individual in itself.

Additionally, through around two hundred job interviews carried out between Spain and United Kingdom in two wellknown international organizations, meeting people of a wide range of different cultures, it has been possible to identify 
what are the several motivations that individuals may have. These will depend mainly on age range, the stage of their professional career and even the situation of the marketplace (economic situation of the country/area).

For example, the youngest candidates on the job interviews, who have just finished college, they aim for a job that could bring them some sort of economic independence in order to be able to start enjoying their adult life, not really concerned about the sort of job. Their priority is having a paid job (safety needs) to start their professional development and also, in some cases, to be able to help at home due to the poor economic situation (physiological needs). In this group, it can also be included all those individuals who, due to the economic crisis have lost their jobs and have no income to pay their bills. All they initially aim for was a job that enabled them to make the ends meet.

The next group of candidates will be those who have gone to university and are looking for a job that is related to what they have studied. The salary may not be an issue at all, as they have the physiological needs mainly covered, their families have paid for their future and their concern is to make the most out of their studies. They obviously want to get paid, but for them, their goal, is starting their career in something really appealing to them, related to their studies. They want a career progression; they want to feel that they can aim for being fully satisfied with their jobs and also with themselves.

There is a third group of individuals, more senior candidates actively looking for a job, irrespective of the reasons, and they focus to get a job paid more or less as much as they get or used to get on their previous-current job, they need to develop their already acquired skills and continue growing as individuals as most of them are now looking to meet their esteem needs.

And the last group will include all those passive candidates that are not really looking for a job as they already have one. They will only be motivated to leave their current position not only if the job offered is for a higher position with possibilities of being promoted based on performance but also if apart from the career progression plan, they get a pay rise.

This does not mean that only individuals in the last mentioned group will be able to reach the top level of Maslow pyramid of needs, but they may be a step closer than the other groups as thanks to their professional development, they are now on a comfort zone where most of their "deficiency needs" are already met.

\section{Extrinsic motivation versus intrinsic motivation (workplace environment)}

There are two differentiated components within the concept of motivation:

A- Extrinsic motivation and

B- Intrinsic motivation.

\section{A. Extrinsic Motivation}

Extrinsic motivation was defined by Brown in 2007 as "the tendency to perform activities for known external rewards, whether they be tangible (e.g., money) or psychological (e.g., praise) in nature." Although there are several definitions for this concept, it is mainly the external means that encourage the individual based upon on performance. These factors will also make the individual adopt a specific position towards some situations and repeat the behaviour if a positive feedback or a reward is provided.

The stimulus that may result in increasing motivation for an individual, may not be the same to the rest, that is why every organization (by means of its line managers) should aim to define in order to be able to create a win-win situation for every individual, as a motivated professional will work more efficiently and that will have a positive impact on organization's performance.

The most influential external means - rewards based on years of empirical study and experience can be synthetized in:

Employment security: the first motivational factor that individuals need is having employment security, especially considering the critical economic moment where redundancy processes are becoming more frequent. Not going to work being afraid of losing the job, will make the individual be less concerned about the situation, which will be translated in not spending time in thinking about being made redundant (this is a time thief which will decrease worker's concentration).

Economic Rewards: almost everyone within an organization will claim that "I am not paid enough for the work I do and the hours I work or the stress I have". This is why a pay rise of a bonus payment will potentially lead to increase worker's motivation at work.

- Feedback - Public Recognition: this is an intangible reward that will help to increase individual's self-confidence and self-esteem, which is likely to increase the motivation to work harder and increase also its efficiency.

Empowerment: although, this may not be as popular as the quoted previously but, it has been demonstrated that, once individuals feel that they are valued and they are given more responsibilities, they will feel that "sort of pressure" that will keep them working harder every day to meet expectations and, if possible, to exceed them too. Consequently, the individual will feel that he/she is vital for the company's success and will feel the commitment to strive for perfection to avoid letting those who believed in him/her down.

Effective internal (verbal and non-verbal) communication: humans are naturally willing to know what is going around in the world and more specifically, in their environment. This is the reason why, every change within the organization, workers would like to know. Communication needs to be clear to allow individuals understand it and needs to be made public in a way that everyone is informed. 
Being transparent in this aspect will prevent gossip and employees will feel that they actually belong to the organization, as they are made aware of every organizational change taking place. Also, it is important to bear in mind that communication is not only about what it is said with words, but also about body language including gestures and even eyes' expression.

- Professional Training: some other individuals also find being trained in the organization as motivational due to the opportunity of acquiring new skills and developing current capacities. Additionally, being trained on different areas, will allow individuals to work on a wider range on activities, increasing their employability.

- Flexible working hours: this is a key factor in order to enable individuals to have a balance between professional and personal life. The opportunity of adapting the working hours in order to be able to liaise with personal needs as far as professional goals and deadlines are met, will be highly motivational for employees.

Working Environment: in this concept, there are several intangible aspects involved such as fairness, equity, honesty, respect and kindness in the way the organization (including its managers, directors and CEO) liaises with the workers. There are situations where individual's working environment, and therefore, his/her comfort zone, are somehow threatened, which will make the worker set up a barrier to feel more protected towards changes, stopping him/her from being more creative, taking active part in the organization and resulting in rejecting new situations. If these changes are not introduced in a smooth and steady way, the working environment will not be the ideal one for the employees to accept them and they will end up rejecting them, weakening their relationships with their organization.

These listed extrinsic motivational factors, have one main drawback, as they do not depend on individuals in themselves, the effect of these is likely to last for a short period of time. For example, if the employee aims to get a pay rise due to an outstanding performance, if he/she gets a pay rise, after a period of time, this will likely not be enough so this will be again a new need to be met.

On the other hand, if what keeps the worker motivated is being provided feedback, hypothetically, if this person is used to get constant compliments on job performance and it happens that the worker expects being praised for the work done on a particular project and does not receive a single comment on it or, alternatively, if the worker has a very poor performance and feedback is provided on this, both facts will lead the individual to a situation of not being happy enough with the work done and the outcome and therefore, he/she will not be highly motivated to keep working hard.
To sum up, external motivational factors can be dangerous as, despite providing temporary satisfaction and incredibly increase motivation, this will not last and, what is even worse, the intrinsic motivational factors (to be studied following this point) will not be important enough as the individual will highly likely be dependent on the external ones.

\section{B. Intrinsic Motivation}

Considering current's work situation and the fast-pacedenvironment where every other day new technologies are released, new implementations and changes take place within programs and organizations, keeping the individuals motivated for the long-term based on external issues, seems an unachievable challenge and this is why intrinsic rewards are so important. What are intrinsic rewards? They are associated mainly to the activity/ project in itself, for its own value and impact on others (clients, suppliers, organizations...).

As with extrinsic motivational factors, there are many intrinsic ones, which will not have the same impact on every individual but will somehow be connected to each other.

In order to exemplify what intrinsic motivators are, the below list includes the most common ones according to previous researches as well as the ones observed in workplace and also through diverse recruitment processes, where identifying candidates' motivations to work was key in order to determine their suitability for the job.:

Career Progression: some individuals may find motivation in career progression. May be they do not have they dreamt job at the moment but, they know that with hard work and positive attitude, they will manage to get as higher in their professional career as they aim to. So, they will work motivated towards a long-term goal which will be becoming reputable professionals in their fields. In order to find the motivation in career progression, it is important to have a set goal in this sense in order to go step by step until getting to the final stage, where they become the professionals they want to be and they have qualified for through years of high performance, which will also make them more demanded professionals in the marketplace.

Personal Ambition: Some employees will find a challenge and even stress or pressure the perfect condition to be able to prove to themselves their value and skills. By challenging themselves and managing to succeed, workers' self-esteem will noticeably increase as this will be rewarded as "personal success" and will encourage the individual to keep his/her own set standards. A person with professional ambition is usually an individual with high tolerance to stress and pressure, who can actually work even better under those circumstances, who challenges himself/herself everyday trying to increase his/her performance and if possible, finding new and more efficient ways of working. This motivational factor is possibly the strongest 
one within the intrinsic motivation as there is nothing more appealing to an individual, than succeeding in every challenge set and seeing the result and impact on others of his/her work.

Integrity and Responsibility: every person (not only working professionals) should ask to themselves if they are who they want to be? If they are the best version of themselves? Which values they would like to see in others? What attitude towards business they would like their managers and colleagues to have? Once all these questions have been answered, it will be possible for those individuals willing to work hard, to increase their intrinsic motivation by setting up objectives to help them have those values and respect from others, which will enable them to be the best professional they can be according to their own parameters and ambitions.

Enjoy: other intrinsic motivator is to love the work done. As Confucius said around 479 BC "Choose a job you love, and you will never have to work a day in your life." This can easily explain why people happily work every day, they actually love what they do, their responsibilities, their opportunities to keep developing themselves as professionals, going to work is no longer a pain but a pleasure.

In the sense of intrinsic or internal motivation, there are many other factors that might be appealing to different individuals but it has been observed that the most effective ones are the factors listed above.

These ones will last in time, do not expire once they have been met as they are based mainly in individual's eagerness to make a better professional of himself/herself and also willingness to learn more to be more qualified and be able to deal with several projects in order to have a more dynamic work which will also increase her/his motivation.

\section{How to build up intrinsic motivation}

Ideally, all individuals should be able to enjoy the benefits of both external and internal motivators however, the external ones, depend on others and therefore, are not possible to control. This shortage of extrinsic motivation can be approached with working harder on the intrinsic motivation.

For example, if the employee needs to be given more power but neither the organization or the managers are acting consequently, this individual should take a proactive attitude towards this situation. How would this be achieved? Once an individual has been given more responsibilities and is able to manage them all successfully, can either ask for more workload or, work in improving current operating procedures.

If feedback is not provided by the company or supervisors, it will be advisable for the individual to set up its own realistic performance indicators in order to be able to identify what is working well and which areas need improvement. By creating its own individual tracker, setting goals to achieve either daily, monthly... the individual will feel highly motivated by the successes and also will find that the mistakes made, create new challenges to embrace and obstacles to overcome.

Alternatively, employees may opt for shaping their jobs to an extent that they can actually enjoy and challenge themselves, helped by those internal motivators that can make the individual be really motivated and willing to do its best at work. Redesigning jobs it is widely called "job crafting" and it relates to the way individual copes with both tasks and other employees of the organization. According to Wrzesniewski \& Dutton (2001), "job crafting is the process of employees redefining and reimagining their job designs in personally meaningful ways". It consists in taking up every opportunity in order to add more value to their work, also, it allows the individual to gain more control over its job, even if it is just over small matters.

According to Hackman (1975), one job will be regarded as meaningful if it has several benefits for the individual grouped in three main dimensions: skills variety, tasks identity and tasks significance. This author also stated that "meaningfulness of jobs is one of the three critical psychological states of job satisfaction; experienced meaningfulness, experienced responsibility and knowledge of result".

Job crafting will be associated for example to situations such as those in which the company has operating procedures that have been used for years but, the individual manages to define a new approach to those procedures, making them more efficient and potentially challenging for the individual.

Being able to build up a strong intrinsic motivation, will be determinant in the success the individual will get as motivation increases efficiency.

Additionally, having strong intrinsic motivation, may improve the attention to detail, being focused not only in finishing the assigned work on the scheduled time, but also in every single detail, will increase personal satisfaction and therefore, will have a positive impact on self-esteem and auto-realization.

\section{Conclusions}

To sum up the main ideas of this article considering all the information studied and through the deep analysis of a series of recruitment processes, the way to differentiate between extrinsic and intrinsic motivation without using other author's words and theories will be wondering: "What makes individuals stay at their current position?" and "What makes individuals strive for perfection in their workplace?".

What makes individuals stay at their current position? It is external motivation what will help retain employees within an organisation for a certain period of time as all their basic needs (deficiency needs according to Maslow) will be temporarily satisfied.

As Michael Lebouf established (1984) "what gets rewarded, gets done", therefore, if something needs to be processed, by means of providing external rewards, the employees will act accordingly to meet expectations and get those rewards. In the other side, if something does not need 
to occur that often, reducing the rewards, there will be an impact on employees' behaviour.

What makes individuals strive for perfection in their workplace? The answer to this question will be "Intrinsic motivation" as it is individuals" own aspirations and interests that keep them focus on achieving their own professional goals.

Although some authors claim that extrinsic motivation has become more unimportant in today's world, both types of motivations are somehow complementary. However, since extrinsic motivation is out of individuals' reach, it will be more advisable to focus on developing the intrinsic motivation in order to facilitate reaching out personal success at work.

Considering what it has been observed in the recruitment processes mentioned previously, there does not seem to be many differences in the motivational factors for individuals, apart from the fact that Spanish economic situation is making individuals look desperately for employment security and a fair salary, which is difficult to find as organizations take advantage of the high demand of jobs and offer workers very poor salaries.

This article may be a base for future researches regarding a wider topic "Positivity to Increase Efficiency". Not many people are aware of the importance of having a positive and proactive attitude at work, simply by smiling; the day will be a bit less difficult.

In this case, being able to work in building intrinsic motivation, something controllable and manageable, will enable to set up a "standard" level of motivation which will encourage proactive behaviours towards work to meet all those inner motivations mentioned before including personal ambition and becoming well-known professionals. Being proactive, will minimize the impact of the so-called "time thieves", reducing the time spent in things that do not add any value to the work and moreover, may help to delay meeting deadlines or paying less attention to detail.

Additionally, in further studies there will be a test defined to identify people's needs and to be able to take action on them. This will be beneficial in terms of being able to keep employees motivated and therefore, to retain the talent within the organisation.

\section{References}

[1] Barrack, M.: 2014 "Extrinsic and Intrinsic motivation and their effect at workplace" - Linkedin.

[2] Brown, L. V.: 2007 "Psychology of Motivation".

[3] Lebouf, M.: 1985 "The Greatest Management Principle in the World".

[4] Martin-Castilla, J.I.: 2004 "Reflexions on Professionals Retentions".

[5] Maslow, A.: 1943 "A Theory of Human Motivation - Hierarchy of needs".

[6] Mayor, L. and Tortosa, F.: 2013 "Perspectives associated to motivation's psychology". Volum VIII.

[7] Thapisa, A.P.N.: 1989 “The Meaningfulness Of Work: Improving The Quality Of Work Life Through Job Enrichment".

[8] Thomas, K.W.: 2000 "Intrinsic Motivation at Work - Building Energy and Commitment" .

[9] Tracy, B.: 2004 "The Four Factors of Motivation".

[10] Vroom, V.H.: 1964 "Expectancy Theory".
About Author:

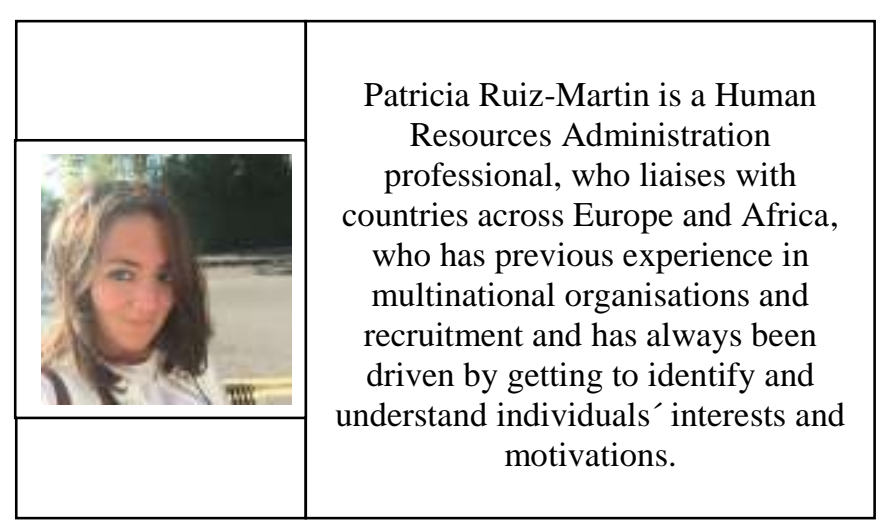

